\title{
"Ask what can you do instead of thinking about what you can't" Profile: Clive Smith
}

Steve Chaplin

Few would disagree that haemophilia presents challenges for everyone who lives with it. Perhaps the greatest of these is being denied the opportunities available to other people through fear of bleeding and joint damage. The regular infusions and clinic appointments that characterise treatment are certainly burdensome, and sometimes traumatic for children and parents alike; but being told 'People with haemophilia can't do this...' is damning in its finality. It is enough to make you demand, 'Why not?' - which is exactly what Clive Smith and a growing number of people in the haemophilia community are asking.

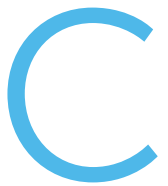

live Smith has severe haemophilia A. He is an athlete who competes at the highest level of ultra-endurance events, of which the best known is Ironman: a 2.4-mile swim, a 112-mile cycle ride and a 26-mile marathon. And yes, all without a break on the same day.

"I think there's an element of being told that you can't do it, so that's exactly what you do," he says. "There's a desire, not in a bad way, to want to prove someone wrong, to push the boundaries and say, 'Actually, I shouldn't be able to do this or people think it's not possible, so let's see if they're right.' Because, ultimately, it's only an opinion, isn't it?"

Health professionals and parents have long been

STEVE CHAPLIN

Medical writer, Haemnet, UK. Email: steve@haemnet.com

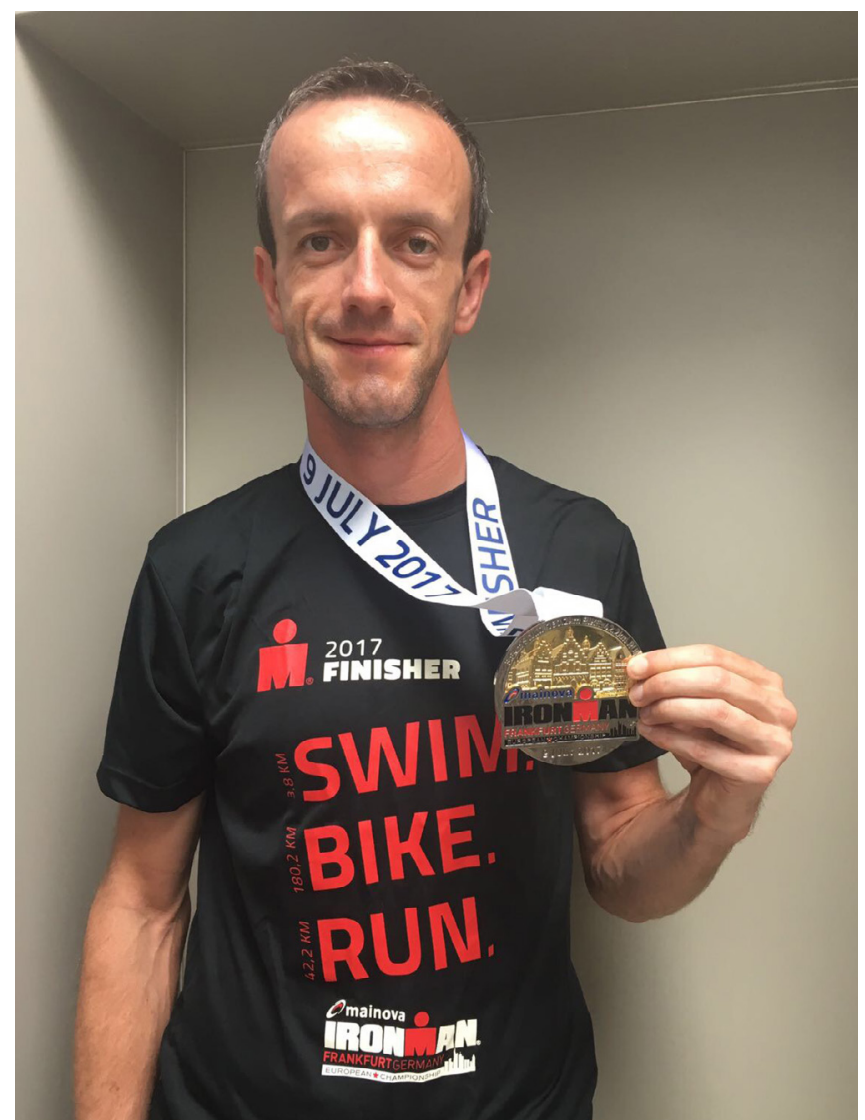

Ultra-endurance athlete Clive Smith - pictured with his medal from the 2017 Mainova Frankfurt Ironman triathlon - has severe haemophilia A and is a trustee of the Haemophilia Society (UK)

protective of people with haemophilia and, in the past, they have discouraged sports participation and physical activity. The culture has now changed: the benefits of an active lifestyle are well established and access to

This is an Open Access article distributed under the terms of the Creative Commons Attribution-NonCommercial-NoDerivs License (https://creativecommons.org/licenses/by-nc-nd/3.0/) which permits use and distribution in any medium, provided the original work is properly cited, the use is non-commercial, and no modifications or adaptations are made. Copyright is retained by the authors. 

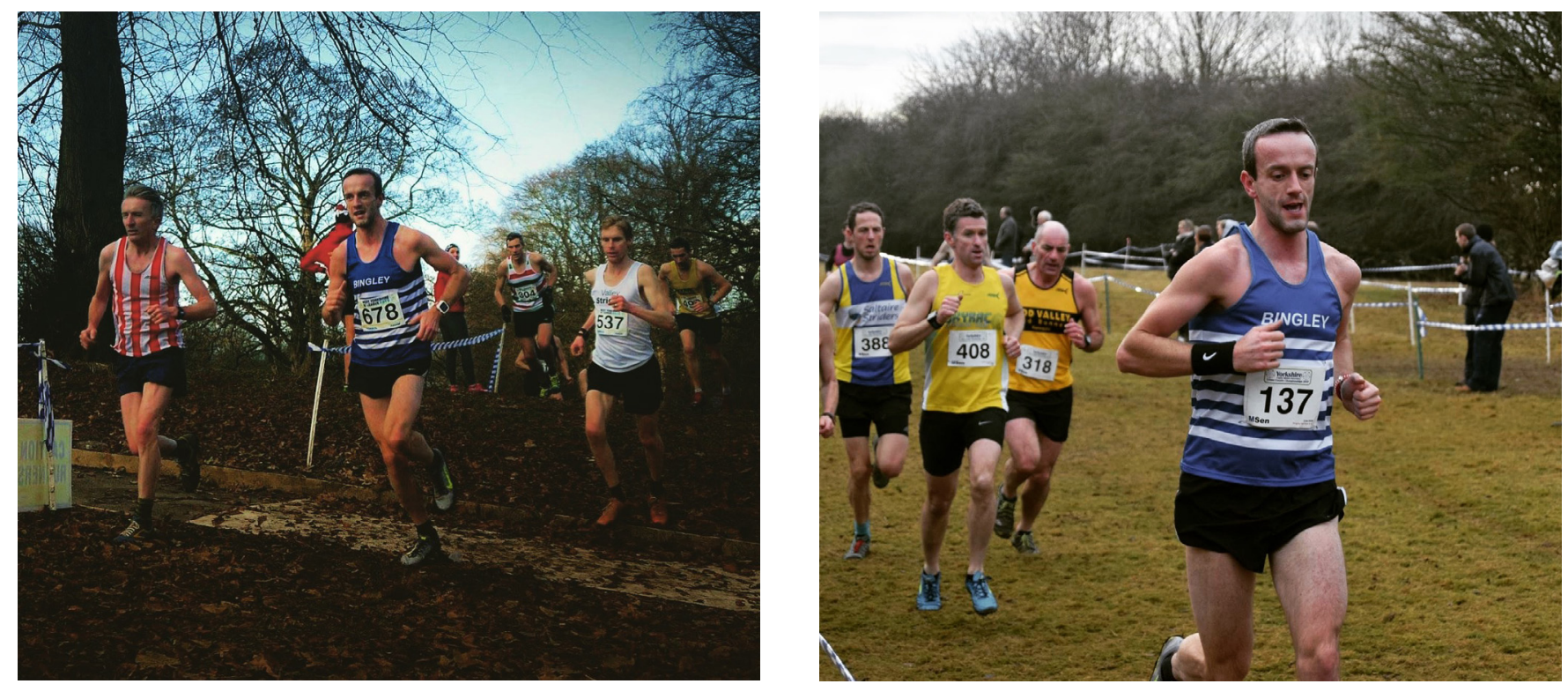

Clive (pictured running in blue and white striped vest) is on prophylaxis three times a week. He injects on the days he runs as this activity potentially impacts his joints more than cycling or swimming

sports and leisure is increasing for everyone, regardless of personal circumstances. Now, the Haemophilia Society's advice ('In general any risk factors associated with sports are outweighed by the inherent benefits of staying active') is much the same as the advice given to the population as a whole, and for the same reasons. Thanks to improved management and in particular the introduction of prophylaxis, the current generations of people with haemophilia are looking forward to growing old just like anyone else. The downside is that, if they have an unhealthy lifestyle, they face similar long-term health risks such as obesity and cardiovascular disease.

Clive Smith was born in 1980, one of three brothers with haemophilia. This was the pre-prophylaxis era and on-demand treatment did nothing to prevent target joints in his elbow and ankle. Spontaneous bleeds were most frequent between the ages of seven and nine; he experienced severe pain and suffered permanent muscle loss in one leg. Clive spent so long in splints and using crutches and wheelchairs that he reckons he was able to walk for only one week in four. His brothers fared little better and he recalls a time when his mother, driving a car that could accommodate two wheelchairs, had to decide which of the three children could best manage without transport. "I never really thought I'd ever be able to play football for the school team or represent the school at sport in any way, shape or form. I never thought of myself, when I was older, as being an athlete," Clive says.

Everything changed with the advent of prophylaxis. "It's not an underestimation to say it was life-changing," he continues. "It went from a stage where everybody knew we were the haemophiliacs or the guys on crutches or in wheelchairs to... we were almost normal again." Clive was able to self-treat three times a week, allowing him to go on school trips and play sports, including football and basketball. His parents were not especially sporty but they supported the boys in what they wanted to do.

For the next ten years or so, Clive's life was much like anyone's with a casual interest in sport: a bit of football and gym work, less so at university as other interests took hold. Broken fingers ended his time as a goalie so he started refereeing. Inspired by his wife, who was then a runner and had completed the London marathon, he developed a lifelong love of running. But then the legacy of childhood haemophilia caught up with him: that ankle brought running to an end within a year, causing pain so severe he could not walk and resulting in admission to hospital. This was another event that changed his future.

Clive pays tribute to Paul McLaughlin, his physiotherapist at London's Royal Free Hospital. With Paul's support and encouragement, he embarked on 18 months of gym work to strengthen his leg muscles to provide sufficient support for the ankle. This was supplemented by short runs, slowly building up to 10-12 kilometres. Eventually, the temptation of longer distances proved irresistible. Clive explains: "When I said to Paul, 'I want to do a half marathon,' he certainly didn't dismiss it and said it was something l'd probably be able to do." Paul's advice had always been to 'be careful and sensible' and even he initially 


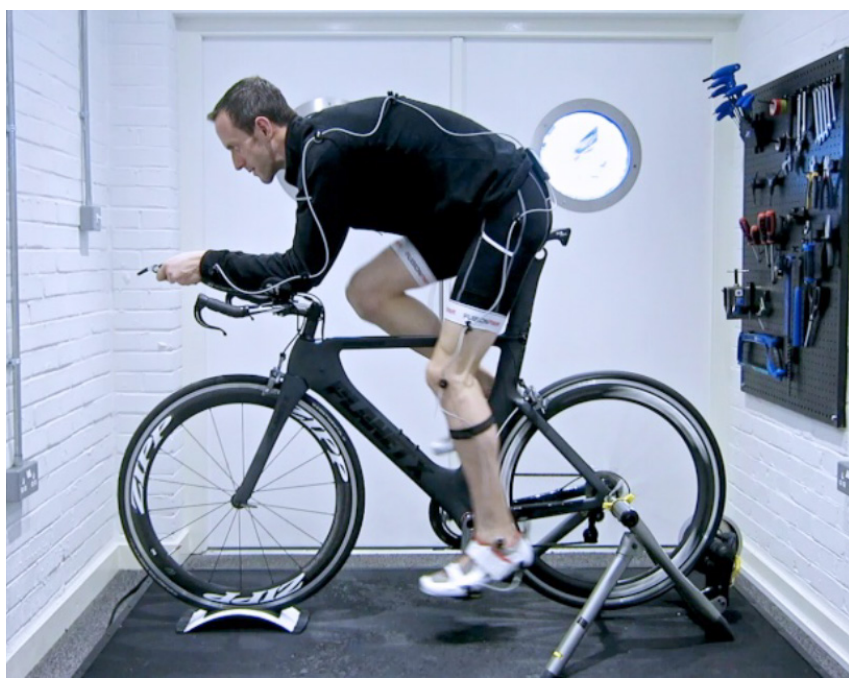

Clive trains hard, with the support of his physiotherapist, and believes that there are valuable benefits to being active: "The more exercise I do, the less bleeds I have"

warned against running a marathon distance. "Things obviously changed," says Clive.

Clearly, that change affected Paul as much as Clive. "He's always been supportive," Clive adds. "I think, had he discouraged me at any step of the way, then it would have caused me to stop and think twice."

The progression from half marathon to marathon to Ironman raises two questions: Why? and How? The why, as we have seen, is fuelled by a defiance of standardised, unquestioned advice originating in a time when haemophilia treatment was barely effective; modern prophylaxis has levelled the playing field for people with haemophilia. "Many of us will have come from generations of families where our predecessors died when they were very young," Clive notes. "I think we owe it to them to live our lives to the maximum with the opportunity that we're now being given by developments in healthcare. I'd certainly encourage people to do what they can with what they've got."

As for the How?, it is important to remember that Clive did not get where he is overnight - it took four to five years to build up to where he is now - or without effort and hard work. Every event is preceded by weeks of preparation and the time commitment demands sacrifices from his wife and at work. His body requires intensive physiotherapy and careful nutrition to cope with the impact of training and competing. However, in these respects, Clive is no different from the athletes he competes with - it is simply impossible to do ultra-endurance events any other way. So the real answer to the question 'How?' is not to be found in the practicalities of training and competing, but in his attitude to living with haemophilia.
"Haemophilia is almost incidental to my life now," he says. "I don't get up and think I'm a haemophiliac or I can't do that because I've got haemophilia, or I shouldn't do that or I should be a bit more careful. In my mind at least, I approach my life as being a normal human being. I think, if anything, it's probably those around me that are a bit more cautious and say, 'Well, should you be doing that?' to which my response is, 'Well, why not?'"

Which is not to say having haemophilia is unimportant. Clive infuses recombinant Factor VIII three times a week, injecting on the day he runs because that activity is potentially harder on his joints than cycling or swimming. The ankle still causes problems: he cannot flex it, so it drags in the water and slows down his swimming. He cannot fully bend his elbow either. And, like any athlete, he has had his share of muscle and tendon injuries. But there are also valuable benefits. "The more exercise I do, the less bleeds I have," he explains. "I know other haemophiliacs who say the same. My twin brother is quite active too and, likewise, the more active he is, the less bleeds he has. The more strength I've got in my muscles and my joints, the better my bone density is from weight-bearing and running, then the fewer bleeds I have.

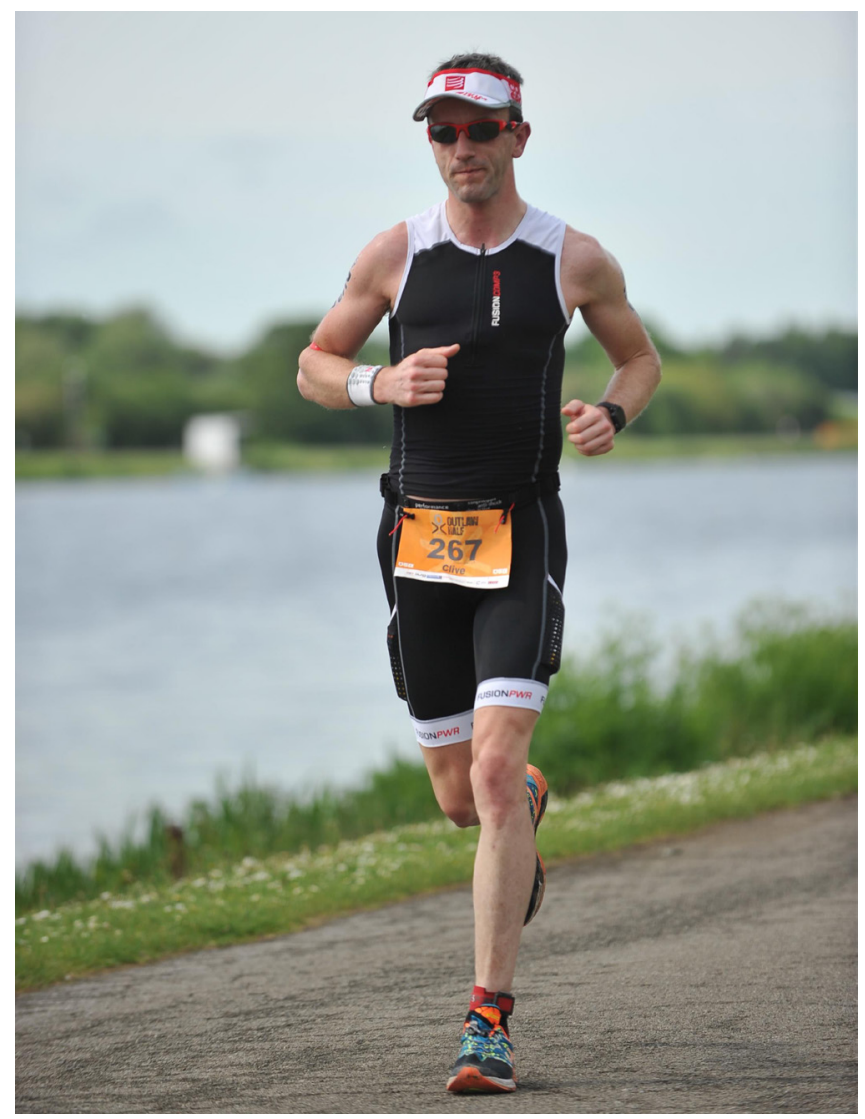

Clive competing in the Outlaw Triathlon, Nottingham, UK, in 2017 
"You hear about people who have problems - they have bleeds and it's a case of, 'Well, what can I do?' And actually, sitting on the sofa, resting, not doing anything, is the worst thing you can do. And there are so many things you can do at home now with a few weights or some stretches, exercise and other things. You don't have to be a member of a gym. It could be as simple as going out for a long walk at times. If anything, I would say being active and being mobile is perhaps more important for haemophiliacs than others."

Clive has always been supported by physiotherapist Paul and haemophilia nurse Kate Khair but he is aware that their enthusiasm for normalising sports participation is not shared by everyone, noting, "I've had very limited experience with centres in the UK, but I'm sure there are some people and some places where they need to change that mentality."

Tens of thousands of athletes complete Ironman and similar events every year, but they are a tiny proportion of the population - not just a tiny proportion of the population with haemophilia, but of the population as a whole. They are clearly exceptional people, whatever their health status, so it is reasonable to question the relevance of their achievements to the ordinary person. "I'm not suggesting everyone goes and does an Ironman tomorrow," says Clive. "But my question is, 'What's your personal Ironman?' I'd certainly say to the younger generation, if I can do this with the joint damage I've had in the past, there should, I hope, be nothing stopping or holding you back. You're a generation behind me and I hope you've had as good if not better care than I've had. On that basis, you've got an even brighter chance and greater possibilities to do things."

What advice about sports would Clive offer a tenyear-old boy and his parents? "Go ahead and do it, but be sensible," he says. "Work with your doctors and physios. Learn from your experiences. You're always going to have knockbacks and have to start again or reset or rethink. Question your limits and ask what can you do instead of thinking about what you can't do."

Clive Smith is Chair of the Haemophilia Society (http://haemophilia.org.uk).

\section{ACKNOWLEDGEMENTS}

The authors have advised no interests that might be perceived as posing a conflict or bias.

Informed consent has been obtained from the individual reported in this article.

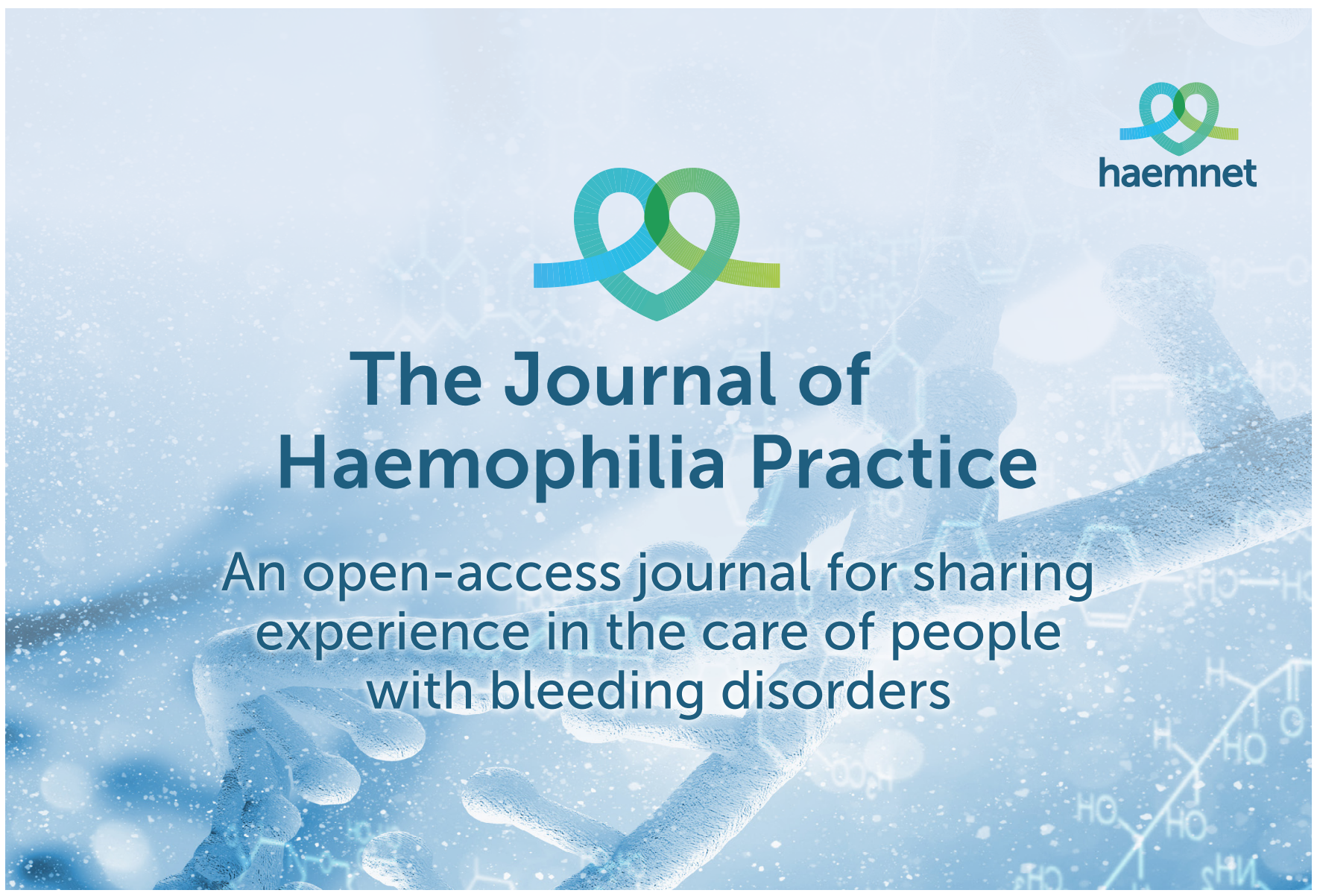

